\title{
Difficulties of Educational Transformation in the Post-Conflict Setting of Kosovo
}

\author{
IAN WINCHESTER \\ University of Calgary
}

This special issue of Interchange documents the thoughts of Kosovar and Canadian researchers active in trying to bring a modern Faculty of Education into being in the University of Prishtina in post-conflict Kosovo. It is important for a journal like Interchange to try to contribute to the dialogue surrounding such attempts, both internal and international attempts, to develop a new educational circumstance in a place devastated by war and by ethnic and religious conflicts with long histories.

Canadians have been engaging in educational reforms for a long time, indeed, for most of the last one hundred and fifty years during which we have had publicly funded common schools and universities. But it has been a long time since we had a conflict of the kind that devastated Kosovo - indeed, not since the aftermath of the Battle on the Plains of Abraham which left Canada with a Kosovo-like population that wished to maintain their own language and religion in the context of the much more powerful and growing dominance of the English language and its related cultures in the North American context.

The story told in the following collection of papers is one of cultural conflict. The most important part of that conflict is internal to the Balkans in general and Kosovo in particular: Serbian regional dominance and the educational reaction of a majority of ethnic Albanians in Kosovo to that dominance. But another kind of conflict is documented in these pages that speak to the well-intentioned concerns of the Canadian International Development Agency work, with professors and staff from the University of Calgary's Faculty of Education. Here we have a conflict between Canadian norms and assumptions about education and those of the local population, especially those who bravely kept a kind of underground Albanian education going during the dark days when the outside Serbian presence was dominant and able to dictate who could teach and what could be taught to whom. The ultimate conflicts between the plans of the international experts and the professoriate in place in the university were probably predictable but apparently unanticipated. 
The Canadian norms and assumptions that were brought to this attempt at the development of a centralized Faculty of Education were themselves, norms and assumptions that had not had a very long history in Canada. They included assumptions about democracy, about the relationships among universities, faculties of education, and publicly funded common schools. They included assumptions about the competences of professors and teachers and of what their proper roles were in contemporary society. They included international educational norms assumed by the European Union, by the United States, and by Canada. For example, they assumed that a university professor is generally someone who is moderately well paid, educated to the doctoral level, and who engages normally in educational research as a matter of course. None of these norms and assumptions could be taken for granted in Kosovo and certainly not at the University of Prishtina, a university with a recent history of Serbian dominance that was only partly countered and democratized in the new millennium.

For a reader of these papers the authors, collectively, document a very important case study for those interested in educational reform, and especially for educational improvement in difficult circumstances.

Ian Winchester

Editor 